\title{
Um olhar arqueológico da saúde pública brasileira
}

\author{
Camila Furlanetti Borges, Tatiana Wargas de Faria Baptista e \\ Ruben Araujo de Mattos
}

Introdução

Em geral, o campo da saúde pública tem contado sua própria história utilizando-se de uma orientação que trata nosso presente como resultado de lutas institucionais - a partir de uma leitura típica das análises de políticas públicas (Baptista et al., 2015) e do movimento da reforma sanitária da década de 1970. Passados mais de 25 anos da criação do Sistema Único de Saúde (sus), há mudanças no cenário político, com novos atores e espaços institucionais, e ampliação do debate - uma história narrada como uma evolução de conflitos, em termos de avaliações e cálculos de estratégias. Todavia, se tomado o objetivo revolucionário enunciado na década de $1970 \mathrm{com}$ a criação de um sistema universal, igualitário e de caráter público (Brasil, 1986), o momento atual configura-se em crise, com o esgotamento das proposições políticas e a reatualização de antigas oposições.

Neste artigo analisamos a saúde pública brasileira pelo viés histórico, para identificar as condiçôes do jogo e os limites a partir dos quais foi possível atuar antes da implantação do sus. Não oferecemos um olhar de reconstituição racional e retrospectiva, mas propomos um ensaio tal como Larrosa o entende, qual seja, um "modo experimental do pensamento", uma escrita de estranhamento do presente: "quando o ensaísta adota a máscara do historiador [...] o que interessa [...] não [é] a verdade de nosso passado, mas o passado de nossas verdades; não a verdade do que fomos, mas a história do que somos, daquilo que, talvez, já estamos deixando de ser" (2004, p. 34). 
Este ensaio resulta de uma análise arqueológica, na acepção de Foucault. Buscamos documentos do campo da saúde pública para construir possíveis descrições do período entre 1950 e 1980 e analisar os discursos que antecederam imediatamente o movimento da reforma sanitária e conferiram-lhe positividade. Nessa perspectiva, o discurso é assumido como um saber, o que permitiu investigá-lo a partir de seu modo de funcionamento e da construção de condições de conhecimento, e não da racionalidade científica.

Analisamos artigos de sete periódicos ${ }^{1}$, selecionados justamente por terem atravessado todo o período em que esta análise está circunscrita, ou a maior parte dele. Os artigos foram tratados como documentos, cuja descrição arqueológica apresenta dois conjuntos de modos discursivos, cada qual com diferentes funcionamentos: a saúde em nome da nação e a saúde pró-desenvolvimentismo.

A seguir, discorremos sobre nossa opção metodológica. Na terceira e quarta partes, apresentamos a descrição dos discursos do campo da saúde pública; na quinta e última parte, mostramos alguns efeitos desses modos discursivos.

Premissas da arqueologia do saber

O título do livro de Foucault As palavras e as coisas, segundo Paul Veyne (2008), é uma traquinagem, pois a obra sustenta que as coisas e as palavras não existem, mas sim aquilo que é praticado e que é dito - ou seja, as práticas discursivas. Assim, Foucault propõe abrir mão de noções universais que coisificam as palavras e as coisas e extirpam sua historicidade.

A intuição inicial de Foucault, premissa do seu enfoque histórico, é a noção de raridade, segundo a qual os fatos humanos "não estão instalados na plenitude da razão [...]; porque o que existe podia ser diferente; os factos humanos são arbitrários [...]" (Idem, p. 314). Como consequência, entende-se que os objetos não podem ser apresentados em termos de verdade, evolução ou racionalidade. Importa discutir o funcionamento da prática, sua materialização e seus efeitos na vida das pessoas.

A arqueologia incide sobre as formações discursivas, que são anônimas, para descrevê-las de maneira sistemática. Não se trata de encontrar origens nem analisar sujeitos pensantes, mas investir na descrição dos enunciados manifestos e nas possibilidades de enunciação, cujas formas se acumulam no tempo e revelam regularidades. O trabalho da arqueologia é colocar em evidência as relações que definem tanto as

1. Arquivos de Higiene e Saúde Pública; Revista Brasileira de Malariologia e Doenças Tropicais; Arquivos da Faculdade de Higiene e Saúde Pública da Universidade de São Paulo; Revista de Saúde Pública; Dados; Revista de Administração Pública e Saúde em Debate. 
possibilidades de enunciação quanto a delimitação que confere sentido e valor de verdade aos discursos.

Além disso, a relação do enunciado com seu sujeito

[...] é uma função vazia, podendo ser exercida por indivíduos, até certo ponto, indiferentes, quando chegam a formular o enunciado; e na medida em que um único e mesmo indivíduo pode ocupar, alternadamente, em uma série de enunciados, diferentes posições e assumir o papel de diferentes sujeitos (Foucault, 2010, p. 105).

Dessa forma, os documentos utilizados neste estudo foram analisados em seu conjunto e reagrupados de acordo com o funcionamento e o modo discursivo. Os discursos serão elucidados a partir de quatro domínios - tempo, espaço, desenvolvimento e Estado -, que designam âmbitos de reconhecimento de condições de possibilidades que atravessam, marcam e extrapolam o campo da saúde.

Dois modos discursivos na saúde

\section{A saúde em nome da nação}

O conhecimento no campo da saúde tem uma longa história de evolução contínua e é progressivamente utilizado. A decisão de aplicá-lo de maneira definitiva significa a solução completa dos problemas acerca da saúde no Brasil. Esse é um modo discursivo presente nos textos da saúde e retrata a ideia de que há um futuro certo da intervenção em saúde. É o que se passa, por exemplo, com o caso da malária. Desde a década de 1960 se diz que a falta de continuidade das ações é o que explica a persistência da doença, pois "não há mais segredos na profilaxia da malária. Todos os seus fatores epidemiológicos são por demais conhecidos” (Pinto, 1961, p. 109). Tem-se a "certeza de que, desta vez, o problema da Malária terá a solução tão esperada" (Idem, p. 120).

A base científica do conhecimento garante o alcance da verdade em se tratando da saúde e da doença. É nesse sentido que Pascale (1958-1959, p. 38) apresentava os avanços das ciências médicas como um "patrimônio da cultura universal", conferindo à função do médico um caráter de função social. Esse conhecimento torna possível vencer diferenças regionais, superarando possíveis obstáculos advindos das especificidades locais.

Mas o que caracteriza um espaço nesse contexto de produção é o modo como o homem o utiliza. Por exemplo, quando o campo da saúde se refere ao sentido econômico, a caracterização não é restrita à identificação dos setores produtivos dominantes, mas contempla várias dimensões do trabalho, como vínculo, posse, 
tipo de produto, rentabilidade da profissão etc. Entre essas dimensões, há uma relação de condicionamento que não tem eixo fixo, e assim os espaços funcionam como zonas movediças.

São frequentemente evocadas diferenças referidas seja ao interior, seja à zona rural, seja ao espaço urbano, mas estes não são espaços que apresentam distinções estanques e definitivas. Por exemplo, o interior é reconhecido como um espaço que engloba o rural, mas, contudo, não exclui o urbano, podendo aí se formar uma interseção. As palavras de Pascale a respeito do hospital rural são ilustrativas:

Quando dizemos "hospital rural" queremos referir-nos ao hospital localizado nas cidades do Interior e destinado, obrigatoriamente a atender também a população rural, [...] de raio de ação condicionado pelos meios de comunicação disponíveis. A cidade representa [...] o centro de gravitação necessário e indispensável, para constituir a sede de hospitais, pela equidistância dos postos de interesse (1950a, pp. 98-99).

O processo de desvelamento da verdade, contínuo e evolutivo, não se deve apenas à evolução da ciência. Segundo Pascale (1958-1959, p. 33), "no crepúsculo da pré-história surgiu o primeiro médico": antes mesmo do surgimento da ciência moderna, a arte de curar contou mais com o espírito heroico de homens dedicados do que com laboratórios e outras instituições, de modo que uma parte da história da medicina se confunde com suas biografias.

Além disso, identifica-se no discurso da medicina uma preocupação de que seu avanço não fique restrito aos profissionais. É importante que os conhecimentos sejam apreendidos por todos, sempre pensando no progresso das próximas gerações, no crescimento da nação e no alcance do mais elevado grau da civilização. Isso posto, aumentam as chances de continuidade das ações de combate aos males da saúde. Estamos falando de ações de educação sanitária.

Essa preocupação, nos idos das décadas de 1950 e 1960, ganhou relevo em função das transformações apontadas pelo Censo de 1960: a aproximação de algum equilíbrio da distribuição populacional entre zona rural e zona urbana, com esta última recebendo maior fluxo migratório.

Numa fase de civilização em mudança, cujo ritmo e cujos efeitos se atropelam, os problemas médicos e os problemas de educação, que se entrelaçam na sua origem e nas suas consequências, defrontam-se com os percalços da predominância do meio urbano. [...]

E à medida em que se igualam na ignorância e se desigualam na heterogeneidade dos valores humanos, erram uns sem teto, arruinados e famintos; espraiam-se muitos na estagnação e na monotonia de ofícios mal remunerados e sem horizonte; vencem alguns e progridem, 
à força de aptidões inatas e mergulham outros na abjeção, no vício e na miséria (Pascale, 1958-1959, p. 43).

Na perspectiva do campo da saúde, processos migratórios desacompanhados de intervenções saneadoras correm o risco de se tornarem perigosos transcursos de errância e desvio. Além disso, é preciso "assegurar as condições mínimas de bem-estar a que têm direito as populações rurais de quase todos os países”, uma vez que conquistas de bem-estar por meio de melhoria das condições de vida "restringem-se, contudo, às condições peculiares às populações urbanas" (Pascale, 1953, pp.4-5, grifo do autor).

Nesse contexto, o urbano era associado à imagem do desenvolvimento industrial e servia a projetos nacionalistas de reformas de base. $\mathrm{O}$ modo de vida urbano era tomado como guia. É aí que encontramos uma importante expressão da educação sanitária dirigida à população rural de forma persuasiva e controlada, para não gerar reação ou conflitos. Essa ação confere positividade ao espaço como zona movediça, homogeneizando diferenças espaciais e equalizando discrepâncias: "cumpre forrar a organização de condições técnicas e didáticas capazes de promover [...] a elevação do plano de cultura, do plano de saúde e do plano econômico do homem rural" (Pascale, 1950b, p. 171).

O campo da saúde extrapola o âmbito puramente biomédico: projeta-se sem conflitos e disputas e potencializa seu próprio conhecimento avançando sobre campos adjacentes. Daí existirem figuras como Artur Neiva, que era "médico, higienista, biologista, historiador, filólogo, político e administrador" (Pascale, 19581959, p. 41). Assim, a saúde angaria autoridade e pode contribuir em considerações de ordem econômica que são relevantes para o quadro sanitário propriamente dito e para um desenvolvimento em nome da nação. Não é de hoje que a saúde é guardiã dos interesses do país e do povo, capaz de encampar um amplo projeto civilizatório. Por isso, discutir questôes como reformas de base e reorganização do Estado certamente é prerrogativa médico-sanitarista.

A saúde investe em uma "reforma de mentalidade" que prescinde de projetos de revolução social. O campo trabalha sem polarizações, compreendendo, simplesmente, que há problemas a resolver, que há conhecimento avançado suficiente para oferecer soluções e que o lugar do Brasil no concerto das nações tem um futuro certo.

\section{A saúde pró-desenvolvimentismo}

Os documentos analisados evidenciam que o campo da saúde avança ao romper distâncias entre aquilo que seu conhecimento alcança e o objetivo que se quer obter. O campo assume uma gama de insuficiências no progresso científico e na 
tecnologia. Nesse sentido, a necessidade de avançar é decorrência dos desafios que se manifestam nas necessidades da população e no reconhecimento das desigualdades na área da saúde nas diferentes regiões do mundo.

O Brasil é reconhecido como parte do mundo subdesenvolvido, mas com uma perspectiva de avanço, desde que se trabalhe de forma orientada, mediante projeções e planejamentos, e sem ficar nas mãos do espontaneísmo, pois o futuro não é certo. O futuro é compreendido como etapista-dualista, assumindo-se que é preciso avançar etapas situando-se entre estes polos de desenvolvimento representativos de desigualdades.

Estudos, geralmente de corte histórico, sobre as experiências desses dois polos de realidade - desenvolvido e subdesenvolvido - visam compreender os fatores determinantes desses diferentes estágios de desenvolvimento e seus reflexos em termos sanitários. Eles subsidiam diagnósticos, planos e projetos de intervenção em saúde mais adequados, tendo em mente também que em nossa atual "fase de desenvolvimento [...] [nossas] comunidades ainda necessitam de uma maior participação do Estado ou de suas Agências para elevar o nível socioeconômico [...]" (Romeiro, 1962, p. 536).

É comum trabalhar agrupando os espaços em função do grau de desenvolvimento e atuando menos em função das singularidades que das identificações. Novais, por exemplo, publicou um estudo de causas de óbito que partia do reconhecimento de que é acentuada "a predominância das chamadas doenças de massa no quadro das causas de enfermidade e de morte nas áreas subdesenvolvidas, dentro de cuja faixa ainda se encontra o Brasil' (Novais, 1962, p. 513, grifo nosso), e isso pode servir de argumento para o planejamento de intervenções comuns nessas regiões.

Além disso, sendo capaz de identificar semelhanças, o campo da saúde pode generalizar parte de seu conhecimento e aproveitar as experiências de regióes mais avançadas, como faz Novais ao reconhecer que, em países desenvolvidos, ocorre uma queda da natalidade com o avanço da industrialização, e conclui:

[...] não dispondo de dados sobre a natalidade diferencial, em meio urbano e rural, no Rio Grande do Norte e tendo em vista a redução da natalidade em consequência da urbanização, fato parcialmente explicado pelo menor coeficiente de nupcialidade nas aglomerações urbanas, é de supor que a natalidade potiguar venha a declinar um pouco em face dos expressivos índices de urbanização que se verifica no Estado. Todavia, uma queda sensível da taxa de natalidade só é de esperar quando venham a ocorrer no Rio Grande do Norte aquelas transformações que redundam numa mudança da estrutura de emprego que a industrialização costuma acarretar (Idem, p. 512). 
Nessa forma de reconhecer os espaços, o campo da saúde sempre estabelece fronteiras nitidas, cuja delimitação é clara o suficiente para que, mediante intervenções que alterem o nível de desenvolvimento, elas mesmas possam ser deslocadas. Além disso, a nitidez permite estabelecer adequadamente taxas que representam quantitativos populacionais em termos sanitários, como mortalidade, natalidade, expectativa de vida etc., e outros dados demográficos.

Pela amplitude de seus objetivos, o campo da saúde esbarra nas insuficiências de suas tecnologias sanitárias. A melhoria do padrão de vida, que tanto reflete como é reflexo do grau de desenvolvimento de um país, exige que o campo da saúde busque suporte de áreas de conhecimento distintas, especialmente profissionais especializados.

Assim, o planejamento, como técnica científica, torna-se indispensável para direcionar as ações e aperfeiçoar os resultados. Em geral, as técnicas de planejamento partem de avaliações conjunturais e estabelecem diagnósticos que permitem eleger critérios e condicionalidades de investimento, prioridades de intervenção e projeções de curto, médio e longo prazo. Também a economia é um importante subsídio que contribui em ações como esta apresentada por Costa:

Foi o que resolvemos tentar em nosso País, com o apoio de alguns economistas, como os mais esclarecidos do Conselho de Desenvolvimento da Presidência da República [...]. Pareceu-nos necessário estabelecer o teto das necessidades calóricas [...], como ponto de partida para a formulação de um planejamento agropecuário adequado, capaz de responder pela conjuntura atual e também podendo servir de subsídio a uma projeção futura das nossas disponibilidades alimentares em face da explosão demográfica brasileira (1962, p. 310).

O olhar que a economia empresta ao campo da saúde ocorre em um contexto de transformação socioeconômica, em que as teorias econômicas desenvolvimentistas ganham relevo, e se expressa em sua abordagem do espaço e dos quantitativos populacionais delimitados a partir de análises de setores produtivos.

As leituras demográficas do campo da saúde interpretam os movimentos migratórios como um "duplo movimento, que comanda o incremento demográfico - o natural ou vegetativo e o migratório ou espacial [...]. Um e outro [...] refletem o grau de desenvolvimento, atingido pela comunidade, bem como a estrutura econômica que aí prevalece” (Idem, p. 511). E mais uma vez apontam as distorções produzidas em termos de desenvolvimento: ao se referir a "desajustes psicológicos e doenças psíquicas", Silva afirma que "o impacto da civilização sofrido pelos que vivem em meio agreste, entregues a uma vida primitiva, de tipo pastoril ou de artesanato elementar, ao penetrarem numa civilização diferenciada, onde a mecanização e a automação já estão em pleno desenvolvimento explica também frequentes desequilíbrios” (1960, p. 81). 
Mas no que diz respeito ao esforço pró-desenvolvimentismo, consolida-se o discurso de que a saúde se organiza não apenas como um campo de conhecimento, mas também como um setor de atuação do Estado. É certo que ela é apenas mais um de vários setores organizados com essa finalidade. Insere-se como componente de um setor mais amplo, genericamente denominado setor social, que pode requerer diálogos com outras áreas sociais nas quais o Estado atua, como educação, habitação, alimentação etc. Mas além dos setores sociais, a saúde continuamente necessita estar em debate com outra área que, no modo de atuação como setor de Estado, opera como que no extremo oposto da corda que esticamos na vontade de desenvolvimento: o setor econômico.

Obviamente, no esforço desenvolvimentista, ambos os setores, cada qual em seu âmbito de ação, podem trabalhar juntos. Segundo Romeiro, “[n]o estágio de subdesenvolvimento em que se encontram muitas das nossas comunidades, os recursos destinados ao melhoramento da saúde ainda devem ser considerados, tanto quanto possível, como um investimento econômico” (1962, p. 538). Mas é preciso estar atento: "O problema que pode surgir [...] é o de equilibrar convenientemente o poder econômico do Estado” (Idem, p. 533). Enquanto setores estatais, o diálogo com a economia frequentemente opera instaurando disputas de projetos políticos, de distribuição de recursos etc.

Trata-se de disputas que - até mesmo no que concerne às teorias interpretativas da relação entre as áreas sociais e a econômica na determinação do desenvolvimento do país - , em seu conjunto, acabam transitando em uma espécie de circularidade de causa-efeito, como se tivéssemos dois polos - o setor social e o setor econômico - que sempre mantêm em aberto o debate sobre a questão de qual deles é capaz de, rompendo a circularidade, alimentar um movimento rumo ao bloco dos países desenvolvidos.

Alguns apostam na ruptura via economia; outros, via saúde. Há também os que simplesmente reconhecem tal circularidade sem optar por uma via específica de ruptura, considerando que o subdesenvolvimento é condicionado por causas múltiplas "e não há possibilidade de eliminá-las parcialmente. Sem a adoção de medidas gerais e radicais, capazes de atender às exigências higiênicas, culturais, econômico-sociais e técnicas, torna-se impossível resolver os problemas do subdesenvolvimento dos nossos países" (Silva, 1960, p. 80).

Sobre como os diferentes modos discursivos enunciam a relação do campo da saúde com o Estado

Explicitamos como as duas regularidades discursivas evocam os domínios tempo, espaço e desenvolvimento. Nos documentos estudados, essas duas formas não se mistu- 
ravam nem se alteravam, por isso dispensamos uma descrição cronológica. Ademais, a cada uma dessas regularidades também correspondem maneiras de enunciar o Estado, as quais serão discutidas separadamente, pois este domínio insere uma importante consideração de ordem cronológica que sugere possíveis inflexões sobre os discursos da atualidade. As regularidades observadas ocorriam quando o Brasil ainda não dispunha de um sistema público de saúde de abrangência nacional e de caráter universal.

A criação do sus em 1988 pode, de um lado, ter funcionado como efeito da influência do modo discursivo pró-desenvolvimentismo, uma vez que regularidade do modo em nome da nação, predominante nos documentos mais antigos, vai perdendo espaço ao nos aproximarmos do início da década de 1970. Por outro lado, pode ter funcionado como materialidade para essa própria predominância e como condição para que se enunciasse o tema do direito à saúde. A seguir, analisaremos o quadro esquemático desses dois modos discursivos (Quadro 1).

QUADRO 1

Modos discursivos do campo da saúde e seus domínios (1950-1980)

\begin{tabular}{l|l|l}
\hline $\begin{array}{l}\text { Modo Discursivo: } \\
\text { EM NOME DA NAÇÃo. }\end{array}$ & Domínıos & $\begin{array}{l}\text { Modo Discursivo: } \\
\text { PRó-DESENVOLVIMENTISMo. }\end{array}$ \\
\hline Futuro certo: há uma verdade da saúde e da doença. & Tempo & $\begin{array}{l}\text { Etapista-dualista: há polos de desenvolvi- } \\
\text { mento, representativos de desigualdades. }\end{array}$ \\
\hline $\begin{array}{l}\text { Zona movediça: os espaços não são estanques nem } \\
\text { definitivos. }\end{array}$ & Espaço & $\begin{array}{l}\text { Fronteira nítida: existem delimitações claras } \\
\text { entre os espaços. }\end{array}$ \\
\hline $\begin{array}{l}\text { Em nome da nação: a saúde como guardiã dos inte- } \\
\text { resses do país e do povo. }\end{array}$ & Desenvolvimento & $\begin{array}{l}\text { Pró-desenvolvimentismo: a saúdeé um setor } \\
\text { de atuação do Estado. }\end{array}$ \\
\hline $\begin{array}{l}\text { Agenciador: prescinde da ideia de atuação do Estado } \\
\text { como de relevância pública na área da saúde. }\end{array}$ & Estado & $\begin{array}{l}\text { Interventor: assume-se o Estado como } \\
\text { espaço institucional no qual são disputados } \\
\text { projetos políticos. }\end{array}$ \\
\hline
\end{tabular}

fonte: Elaboração dos autores.

\section{O campo da saúde em nome da nação e o funcionamento discursivo do Estado}

Um dos modos de atuação do Estado na saúde é operar sobre a economia no manejo da distribuição de médicos e estabelecimentos de saúde do setor privado. No entanto, também opera nas ações de saúde de natureza pública; na verdade pouco importam os limites de atuação e as diferenciações entre uma e outra esfera.

Tanto é assim que ao referir-se, por exemplo, à quantidade de hospitais por natureza jurídica, Pascale os diferencia entre gratuitos e não gratuitos - "62\% dos hospitais existentes no Estado são destinados a serviços gratuitos” (1950a, p. 98) - e esclarece que das unidades hospitalares gerais no estado de São Paulo, dezenove são oficiais, 89, particulares, doze, mistas, e 198, filantrópicas. A importância de diferenciar 
esses leitos, não em função de serem públicos ou privados, mas em função de serem gratuitos, é porque o campo da saúde lida com necessidades advindas de "exigências da vida”, e não de necessidades formais.

O campo da saúde faz distinção entre serviços privados e públicos, mas com vistas a destacar as "restrições naturais" de uns e as "limitações ocasionais" de outros, respectivamente. É nesse sentido que Pascale, propondo um plano de interiorização da assistência que tivesse "portas abertas para todos os médicos e para toda a gente, sob a ambição decidida de oferecer os mesmos benefícios a todos", conclui que tal iniciativa "não poderá resultar exclusivamente da iniciativa particular, nem da caridade pública" (Idem, p. 99, grifo nosso). Sob o imperativo de que "não se pode conceber a elaboração de qualquer plano assistencial de interesse para o Interior do Estado, que não vise, desde logo, o total abrangimento da população rural” (Idem, p. 98), o que importa é ampliar a cobertura, mesmo que a custo de alguma promiscuidade entre a ação pública e a privada.

A propósito, quando considera a ação pública uma "caridade”, o campo da saúde está afirmando que prescinde da ideia de atuação do Estado como de relevância pública na área da saúde. Se a sustentabilidade do conjunto hospitalar é mantida "por força dos imperativos da solidariedade humana e dos auxílios um tanto desordenados do Estado" (Idem, ibidem), o que se configura é apenas um modo de viabilidade financeira. Para o campo da saúde, o Estado é compreendido através de sua atuação como Estado agenciador.

De qualquer maneira, existe um olhar crítico sobre a atuação do Estado, o que recorrentemente se transforma em desqualificação da ação política. Por exemplo, depois de afirmar a valorização dos “métodos não visando lucros de medicina”, Pascale explica que tais métodos existem sob duas formas - " 1 - Medicina compulsória do Estado; 2 - Organização sanitária, não política, dos consumidores para suprir-se de serviços médicos" - assim compreendidas:

1 - O sistema de controle pelo Estado, surge, naturalmente, como resultado da ineficiência e fracasso do método do negócio competitivo. [...].

2 - A organização voluntária dos pacientes [...]. Os hospitais de ordens religiosas [...] são dessa natureza. [...] os associados empregam médicos diretamente [...].

O sistema de medicina cooperativa representa uma socialização da medicina não política, voluntária, particular, não visando lucros. O método cooperativo voluntário é o oposto da socialização da medicina pelo Estado (Idem, p. 102, grifo nosso).

Como efeito, o campo da saúde atribui legitimidade às ações que partem do privado porque não se trata de ações políticas, mesmo que eventualmente recebam 
subvenção estatal, como é o caso do exemplo citado por Pascale como "organização voluntária”: os hospitais de ordens religiosas.

Para enfrentar as distorções que a política imprime ao campo da saúde, o que se propõe é o apoio daquilo que se considera o maior esteio da medicina, o que garante seu futuro certo: a ciência - compreendida como isenta de interesses políticos.

\section{O campo da saúde pró-desenvolvimentismo e o funcionamento discursivo do Estado}

Para o campo da saúde, nesse modo discursivo, o Estado é um espaço institucional em que são disputados projetos políticos representados por diversos grupos de interesse, estando ou não no governo. E toda ação política deve vir acompanhada de uma justificativa, sendo preciso enfrentar o debate sobre quais ações competem ao Estado. Isso é importante até mesmo como esforço de delimitação do Estado. Romeiro, por exemplo, entra nesse debate defendendo que

[...] empresas responsáveis pelo abastecimento de água têm uma finalidade social sanitária mais importante que a finalidade econômica; daí porque se generalizou [...] a administração [...] direta ou indiretamente, pelos órgãos do Governo. [Outras empresas] [...] têm um fim utilitário diferente, [...] pois os interesses econômicos estimulam a sua organização" (1962, p. 536).

A partir de sua delimitação, o Estado pode e deve assumir-se como Estado interventor, cunhando uma diferenciação em relação à esfera privada. É mediante tal compreensão que o campo da saúde assume disputas importantes vinculadas a interesses diversos. No que diz respeito à prestação de assistência hospitalar, por exemplo, Fauze Carlos elege alguns “aspectos principais” sobre um projeto:

Este critério de assumir o Estado a responsabilidade direta às populações demonstra evidentes inconvenientes, destacando-se o custo mais oneroso, a eficiência reduzida e ausência de uma distribuição equitativa do ponto de vista social.

[...] O desenvolvimento da iniciativa estatal direta nesse setor, condiciona consequentemente retraimento da participação privada, mais apta (1958-1959, pp. 18-19).

Os argumentos giram em torno da eficiência das esferas pública ou privada, da rentabilidade das ações etc. A princípio, como campo, a saúde não se posiciona a favor ou contra o Estado ou o setor privado. A propósito, a defesa ou a recusa da competência do Estado em determinada área pode ser sustentada em critérios conjunturais, em coerência com o modo de compreensão do tempo etapista-dualista. Nesse sentido, Romeiro assevera que a "conjuntura econômica dos países em regime 
inflacionário [...] não propicia investimentos [...] em serviços de utilidade pública" (1962, p. 531).

\section{Discussão e conclusão}

Os dois modos discursivos apresentados produziram efeitos importantes, sustentando diferentes disputas no debate político que antecedeu a criação do sus.

Sobre o modo da saúde em nome da nação, vale destacar que os enunciados produzem um amálgama entre as esferas pública e privada, e nesse sentido o Estado figura de certo modo indiferenciado, apenas como uma espécie de órgão agenciador. Nos documentos identificados com esse tipo de enunciação despontavam temas ou estratégias com uma vontade de mudanças sem rupturas, mas com uma aposta de transformação civilizatória. Também não apresentavam projetos que sustentassem a saúde como objeto de reivindicação de direitos. A delimitação do Estado não é nem objeto de conflito nem de discurso, e sem essa delimitação parece não haver possibilidade discursiva para a emergência de um debate sobre cidadania. Assim, embora se defendesse a "total abrangência da população" quanto aos serviços de saúde, isso não configura um movimento de universalidade e igualdade de direitos.

Em meados da década de 1960, esse modo discursivo apresentou seus enunciados em um contexto diferente, quando se anunciava um outro modo de articulação: o pró-desenvolvimentismo. Apresentam-se discursos de reconhecimento de pertença a um passado - "Pertenço quase como 'Último dos Moicanos' a uma geração que deflagrou o movimento de Saúde Pública no Brasil [...] há 40 anos” (Ferreira, 1963, p. 512) - e de crítica aos movimentos que positivam esse outro modo discursivo: "O fato de hoje se debruçarem em seu exame em suas implicâncias não apenas homens, mas escolas de pensamento econômico, permite concluir que a débil tendência de 'vender' programas de saúde à boa vontade dos governantes, hoje se transformou num imperativo em que apenas se discutem prioridades" (Idem, p. 509). O autor, apresentando o saldo médico-sanitarista que nos serve como reconhecimento desse contexto, então conclui:

Se pudéssemos apresentar nossa conta ao Governo da Nação [...], o nosso crédito bastaria para enfrentar, assegurando resultados, uma série de problemas que agora só tomam existência nos planos de economia ou nas recomendações de contenção de despesas.

Os resultados dessas conquistas não nasceram de nenhuma modificação da estrutura econômico-social do Brasil.

Queremos, podemos e devemos tomar parte na obra de desenvolvimento do País, que não é nem descoberta de agora [...] mas fruto do trabalho [...] de todas as gerações que nos antecederam (Idem, p. 513). 
No modo discursivo em nome da nação, o campo da saúde sabe o que deve ser feito para resolver definitivamente o conflito entre a saúde e a doença e construir o Brasil como nação do futuro. Os resultados alcançados, sobretudo a partir do início do século $\mathrm{xx}$, foram absolutamente relevantes ao desenvolvimento nacional. Se em meados dos anos de 1960 foram discutidas as reformas de base e a reorganização do Estado, não há razão para se prescindir do conhecimento dos sanitaristas.

Quanto à maneira pela qual o discurso pró-desenvolvimentismo enuncia o Estado, diferente do discurso em nome da nação, criou-se uma fronteira nítida em torno daquilo que é o Estado e o que a ele compete, assim como em relação ao que é público ou privado, ou ainda no que diz respeito às formas pelas quais essas esferas se relacionam. Trata-se de um jeito de enunciar o Estado que o diferencia na medida da possibilidade de identificá-lo como interventor nas esferas pública e privada.

Isso não quer dizer que as diferenças significam o silenciamento de promiscuidades. Ao expor um posicionamento em favor do público ou em favor do privado, o que esse modo discursivo materializa é uma disputa e não a ligação com um ou outro interesse a priori. Assim, a oposição entre Estado e privado, mesmo que apareça como uma questão "formal" ou "burocrática", como a tal da "eficiência”, é apenas efeito do Estado interventor, que não está amalgamado com o privado.

Os argumentos que associam eficiência, rentabilidade e setor privado são efeitos de superfície, ou melhor, polêmicas do modo discursivo. Por exemplo, é certo que o setor hospitalar era mais custoso nos idos da década de 1960, porém o aumento do custo, em princípio, não tem peso diferenciado para o setor público ou privado nem causa impactos diferentes na eficiência desses setores. Sobre essa discussão, Mello afirma: "Um dos mais correntes argumentos contra a intervenção do Estado nos mais diversos setores, e cada vez mais amplamente, é a propalada ineficiência da administração pública" (1965, p. 322). Todavia, baseado no estudo de Benedito Silva, ele continua: "as empresas privadas, sobretudo as grandes empresas, padecem dos mesmos males das organizações governamentais, inclusive o nepotismo, o favoritismo e todos os demais fatores decorrentes do elemento pessoal, comum a ambos os tipos de empresas" (Idem, p. 322, grifo do autor).

Além disso, se fosse possível ligar diretamente eficiência e rentabilidade para defender a ideia de que o Estado não é eficiente no setor hospitalar, seríamos forçados a acreditar que o setor se tornou rentável apenas a partir de 1960 ou a negar que o Estado tenha, antes disso, custeado o setor hospitalar por meio de convênio com instituições privadas. Ou seja, para sustentar que eficiência é atributo do setor privado, deveríamos, supor que as subvenções - que já ocorriam desde há muito tempo - seriam uma necessidade inédita dos anos de 1960, decorrente do aumento do custo do setor hospitalar e como estratégia de garantia de sua rentabilidade. Mas, em 
termos de financiamento, a separação entre benefícios e investimentos não anula um histórico de subvenções estatais. Ademais, o Estado interventor funciona articulado com o pró-desenvolvimentismo, na medida em que a diferenciação do Estado passa pela positivação de ações de relevância pública, entre as quais aquelas voltadas para o desenvolvimento do país. Assim é que

[...] também o Estado interfere, em escala significativa, no setor da saúde da coletividade. Ainda porque não se justificaria excetuar a assistência hospitalar da ação estatal, desde que está diretamente relacionada com a defesa dos interesses da comunidade. A saúde, como a educação, está estreitamente vinculada com o nível de vida e com o complexo problema do desenvolvimento econômico (Idem, p. 321).

Como o pró-desenvolvimentismo mobiliza a questão da distributividade, "restaria a imperiosa necessidade da iniciativa governamental com o objetivo de atenuar as consequências sociais das desigualdades de desenvolvimento econômico nas diversas regiões do País" (Idem, p. 329). Assim, o arranjo discursivo que permite tomar as desigualdades como um problema é o mesmo que aquele cujos documentos tematizam algo muito caro aos embates estabelecidos na conjuntura da criação do sus e até os dias de hoje: questões de cidadania e igualdade de direitos.

Conforme apontamos, no início do período analisado, entre 1950 e 1980, foi predominante o modo discursivo em nome da nação, mas isso se inverte em meados da década de 1970. Cumpre apontar o que pode ter sido uma ruptura advinda da relação entre o modo pró-desenvolvimentismo e a criação da sus: se esta funcionou para materializar a predominância do discurso pró-desenvolvimentismo e foi condição para o surgimento de enunciados sobre o tema do direito à saúde, parece que permitiu também a emergência de outras disputas em torno do sentido político-estratégico do desenvolvimento, especialmente em sua relação com a economia. Ou seja, o discurso que descrevemos, manifestado antes da criação do sus, operava uma delimitação do Estado, no interior do qual os setores da saúde e da economia se relacionavam ora cooperativamente, ora competitivamente. A relação que se instaurava era em torno da questão sobre qual seria o ponto de ruptura do subdesenvolvimento e quais seriam os investimentos feitos no setor saúde. Hoje, ao lado disso, configura-se um manejo da saúde como setor estatal de desenvolvimento econômico, diretamente produtivo: menos do que investimentos em saúde, tratamos atualmente de investimentos feitos pelo setor da saúde, por dentro do Estado. Muitas são as implicações para a defesa de um sistema que se pretende universal, igualitário e de caráter público. Nesse sentido, apontamos para a necessidade de se investigar as estratégias discursivas da saúde a partir de 1980, atentando especialmente para o funcionamento discursivo 
dos enunciados sobre direito e desenvolvimento. Podemos lançar como hipótese uma possível inflexão na própria noção de direito como igualdade entre os cidadãos.

\section{Referências Bibliográficas}

Baptista, Tatiana Wargas de Faria et al. (2015), "Sobre as contribuições da arqueologia do saber para estudos da saúde coletiva”. In: (orgs.). Politicas, planejamento e gestão em saúde: abordagens e métodos de pesquisa. Rio de Janeiro, Editora Fiocruz.

Brasil. Ministério da Saúde. (1986), Relatório final da $8^{a}$ Conferência Nacional de Saúde. Brasília, Ministério da Saúde.

Carlos, Fauze. (1958-1959), “A saúde pública no Plano de Ação”. Arquivos de Higiene e Saúde Pública, 75-82 (23/24): 9-21.

Costa, Dante. (1962), “Problemas de nutrição e saúde pública”. Revista Brasileira de Malariologia e Doenças Tropicais, 3 (14): 307-312.

Ferreira, Manoel José. (1963), "Perspectivas atuais da saúde pública”. Revista Brasileira de Malariologia e Doenças Tropicais, 3 (15): 505-513.

Foucault, Michel. (2010), A arqueologia do saber. Rio de Janeiro, Forense Universitária.

LARrosa, Jorge. (2004), "A operação ensaio: sobre o ensaiar e os ensaiar-se no pensamento, na escrita e na vida”. Educação \& Realidade, 1 (29): 27-43.

Mello, Carlos Gentile de. (1965), “A intervenção do Estado na assistência hospitalar”. Revista Brasileira de Malariologia e Doenças Tropicais, 2/3 (17): 319-331.

NovaIs, Menandro. (1962), "Levantamento da situação demográfica e econômica do estado do Rio Grande do Norte: contribuição para o estudo de seu problema alimentar”. Revista Brasileira de Malariologia e Doenças Tropicais, 4 (14): 501-529.

PAsCale, Humberto. (1950a), "Contribuição para a elaboração de um plano de assistência hospitalar no interior do estado”. Arquivos de Higiene e Saúde Pública, 44 (15): 97-107.

. (1958-1959), “Contribuição para a história da saúde pública em São Paulo". Arquivos de Higiene e Saúde Pública, 75-82 (23/24): 32-48.

. (1953), "Novos rumos sobre a recuperação do Homem Rural - Parte Primeira: A educação em função da saúde pública”. Arquivos de Higiene e Saúde Pública, 55 (18): 3-23. . (1950b), "Serviço público e socialização da medicina". Arquivos de Higiene e Saúde Pública, 45 (15): 165-175.

Pinto, S. C. Ferreira. (1961), "A malária e o homem rural: trabalhos de campo". Revista Brasileira de Malariologia e Doenças Tropicais, 3/4(13): 107-121.

Romeiro, Luiz. (1962), "Relações entre as diversas agências de governo e os abastecimentos d'água potável". Revista Brasileira de Malariologia e Doenças Tropicais, 4 (14): 531-542.

Silva, A. C. Pacheco e. (1960) "A higiene mental nos países subdesenvolvidos." Arquivos de Higiene e Saúde Pública. São Paulo, 84 (25): 79-82. 
VEYNE, Paul. (2008), "Foucault revoluciona a história”. In: . Como se escreve a história. Lisboa, Edições 70.

\section{Resumo}

Um olhar arqueológico da saúde pública brasileira

Com base na análise arqueológica de artigos da saúde publicados entre 1950 e 1980, foram descritos enunciados e regularidades a partir de quatro âmbitos: tempo, espaço, desenvolvimento e Estado. Dois modos discursivos foram identificados: em nome da nação e pró-desenvolvimentismo. O primeiro não enunciava reivindicação de direitos, e o segundo relacionava direito, saúde e desenvolvimento com a delimitação do Estado e das ações de relevância pública. Aponta-se para a necessidade de investigar as estratégias discursivas da saúde a partir de 1980, atentando especialmente para o funcionamento discursivo dos enunciados sobre direito e desenvolvimento, pois talvez tenha ocorrido uma inflexão na própria noção de direito como igualdade entre os cidadãos. Palavras-chave: Reforma sanitária; Campo da saúde; Análise arqueológica.

\section{Abstract}

An archaeological outlook on public health in Brazil

From an archaeological analysis on health articles published between the years of 1950 and 1980, it was described statements and regularities coming from four fields: time, space, development and State. Two discursive modes were identified: on behalf of nation and pro-developmentalism. The former did not declare the claim of rights; the latter associates law, health and development with State and relevant public actions delimitations. This points to the necessity of investigating health discursive strategies since 1980 especially considering the discursive functioning of the statements about law and development because an inflexion of the very notion of law as equality among citizens may have occurred.

Keywords: Sanitary reform; Health field; Archaeological analysis.

Texto recebido em 17/8/2015 e aprovado em 15/12/2015. DOI: 10.11606/0103-2070.Ts.2016. 102344

Camila Furlanetti Borges é professora-pesquisadora da Escola Politécnica de Saúde Joaquim Venâncio (EPSJV/Fiocruz) e doutora em saúde pública pela Escola Nacional de Saúde Pública Sergio Arouca (ENSP/Fiocruz).E-mail: camilaborges@fiocruz.br.

Tatiana Wargas de Faria Baptista é professora-pesquisadora da Escola Nacional de Saúde Pública Sergio Arouca (ENSP/Fiocruz) e doutora em saúde coletiva pelo Instituto de Medicina Social (Ims/Uerj).E-mail: twargas@ensp.fiocruz.br.

Ruben Araujo de Mattos é professor-adjunto do Instituto de Medicina Social (IMs/Uerj) e doutor em saúde coletiva pelo IMs/Uerj. E-mail: ruben@ims.uerj.br. 